\title{
Differentially expressed genes in healthy and plum pox virus-infected Nicotiana benthamiana plants
}

\author{
Z. VOZÁROVÁ ${ }^{1}$, M. ŽILOVÁ ${ }^{2}$ Z. ŠUBR ${ }^{*}$
}

${ }^{1}$ Institute of Virology, Slovak Academy of Sciences, Dúbravská cesta 9, 84505 Bratislava, Slovak Republic; ${ }^{2}$ Commenius University, Faculty of Natural Sciences, Mlynská dolina, Bratislava, Slovak Republic

Received June 23, 2015; revised July 22, 2015; accepted October 15, 2015

\begin{abstract}
Summary. - Viruses use both material and energy sources of their hosts and redirect the production of disposable compounds in order to make viral replication more efficient. Metabolism of infected organisms is modified by these enhanced requirements as well by their own defense response. Resulting complex story consists of many regulation events on various gene expression levels. Elucidating these processes may contribute to the knowledge on virus-host interactions and to evolving new antiviral strategies. In our work we applied a subtractive cloning technique to compare the transcriptomes of healthy and plum pox virus (PPV)-infected Nicotiana benthamiana plants. Several genes were found to be induced or repressed by the PPV infection. The induced genes were mainly related to general stress response or photosynthesis, several repressed genes could be connected with growth defects evoked by the infection. Interestingly, some genes usually up-regulated by fungal or bacterial infection were found repressed in PPV-infected plants. Potential involvement of particular differently expressed genes in the process of PPV infection is discussed.
\end{abstract}

Keywords: virus-host interaction; gene expression; subtractive hybridization

\section{Introduction}

Viruses are traditionally connected with diseases. It results from the fact that pathological changes enabled the discovery of their etiological agents and are logically in the center of interest concerning human, animal or plant health. Currently, modern laboratory tools enabled to discover that the constitution of living organisms is much more complex,

${ }^{*}$ Corresponding author. E-mail: virusubr@savba.sk; phone: +4212-59302447.

Abbreviations: $\mathrm{APX}=$ ascorbate peroxidase $\mathrm{CAB}=$ chlorophyll a/b-binding protein; DSPP = dentin sialophosphoprotein; $\mathrm{FRL}=$ Frigida-like protein; GCS = glycine cleavage system; $\mathrm{HMGB}=$ high mobility group $\mathrm{B}$ protein; $\mathrm{JA}=$ jasmonic acid; $\mathrm{MLP}=$ major latex protein; $\mathrm{MT}=$ metallothionein $\mathrm{PI}-\mathrm{PLC}=$ phos phoinositide-specific phospholipase C; $\mathrm{PPV}=$ plum pox virus; PRG = photosynthesis-related gene; PS II = photosystem II; ROS = reactive oxygen species; SNS = S-norcoclaurine synthase; SUMO = small ubiquitin-related modifier; TLP = tetraspanin-like protein; $\mathrm{Ub}=$ ubiquitin including plenty of cellular or subcellular species, as well as adapted and horizonatally migrating genes in the frame of each multicellular body. Although many such intercellular "passengers" contribute potentially to the evolution of their „vehicle", from the practical point of view pathogenic organisms remain more important in the short term. Comparative studies on various molecular levels (transcripts, proteins) may help to better understand the relations between pathogens and their hosts (Haft, 2015).

$N$. benthamiana is a model species widely used in plant virology because of its sensitivity to a broad spectrum of viruses, usually systemic infection and easy maintenance (Goodin et al., 2008). It is a proper propagative host also for viruses naturally infecting perennial plants, such as plum pox virus (PPV). We have extensively used this artificial host plant species, e. g. for multiplication of emerging PPV strains, as primary target for developing biolistic technique, for analysis of PPV strain competitiveness and of mutations accumulated in the PPV genome, or for expression of foreign genes cloned in the PPV genome (Glasa et al., 2004; 2010; Predajňa et al., 2010; Šubr et al., 2012; Kamencayová 
et al., 2014). Here we attempt to compare the transcripts from healthy and PPV-infected $N$. benthamiana plants to reveal the regulatory effects in the course of systemic viral infection.

\section{Material and Methods}

In vitro cultivated $N$. benthamiana lines were established from plants infected by PPV-Rec (isolate BOR-3) (Glasa et al., 2004) and from healthy plants. Two hundred mg of leaf tissue from each line were used for total RNA isolation by Agilent Plant RNA Isolation Mini Kit (Agilent Technologies). In-Fusion SMARTer Directional cDNA Library Construction Kit (Clontech) was applied to prepare double stranded cDNA, which was subjected to subtractive hybridization exactly as described (Šubr et al., 2002). Each sample (healthy and infected) was analysed both as the driver (digested by $A l u \mathrm{I})$ and the tracer (digested by EcoRI). Reconstituted fragments were cloned to EcoRI-digested pBluescript SK II, transformed into E. coli JM109 and obtained clones were analysed by colony PCR using insert-spanning primers. The amplimers were sequenced and subjected to BLAST analysis.

\section{Results and Discussion}

Typically, tens to thousands clones harboring differentially expressed genes are obtained by subtractive hybridization techniques. In our experiment, 217 and 12 clones represented genes induced and repressed by PPV infection, respectively. The length of inserts ranged from 250 to $1500 \mathrm{bp}$. Only clones containing inserts longer than $750 \mathrm{bp}$ from the first set and all twelve clones from the second set were selected for sequence analysis. Obtained results are summarized in the Table 1. Influenced genes coded for proteins implemented in various biochemical reactions. Causal connection with general stress or pathogen attack could be relatively clearly outlined for most of them. Several up-regulated genes were directly or indirectly connected with reactive oxygen species (ROS) production or relevant signal transduction. Short description of potential involvement of induced genes in plant response to virus infection follows.

Plant metallothioneins (MTs) are small cystein-rich proteins involved in binding of mono- and divalent metal ions, essential for metal homeostasis and detoxification (Leszczyszyn et al., 2013). Induction of MT production has been observed in various plants after infection by bacteria, phytoplasmas or fungi. Connection of MT expression with different stress conditions including virus infections of plants has been recorded, particularly when senescence-like symptoms occurred (Choi et al., 1996; Kim et al., 2001). Rather then to direct interaction with pathogens, it may be related to the general „out-of-balance“ level of particular molecular compounds resulting from the infection and the tendency of the host to renew its cellular homeostasis. The mechanism of MT action may be also related to antioxidative properties of its tiol groups (Carginale et al., 2004). Under stress conditions namely, enhanced concentration of ROS can cause significant cell damage. During microbial infection a transient accumulation of $\mathrm{H}_{2} \mathrm{O}_{2}$ causing localized programmed cell death leads to preventing further pathogen spread in the plant. Antioxidative compounds protect other host tissues from this action.

Another protein found in our work to be up-regulated during virus infection, ascorbate peroxidase (APX), has also a role in the protection against oxidative stress by ROS detoxification. It is the key enzyme of the ascorbate-glutathione cycle catalyzing the conversion of $\mathrm{H}_{2} \mathrm{O}_{2}$ into water, using ascorbate as the donor of electrons. It may be activated in chloroplasts as well as in cytoplasm, mitochondria or peroxisomes (Caverzan et al., 2012). Only weak constitutive expression of rice APX has been recorded under standard conditions, while strong transcriptional up-regulation occurred upon various stress events including wounding or fungal pathogen attack (Agrawal et al., 2003). In another case, the grapevine APX was 3-times more accumulated in Botrytis cinerea-infected tissues, however, without enhancement of its transcription (Dadakova et al., 2015). Enhanced APX activity has been found also in virus-infected plants (e. g. citrus tristeza virus in Mexican lime; Pérez-Clemente et al., 2015). Interestingly, APX activity was induced by PPV infection only in a susceptible (contrary to a resistant) apricot cultivar (Hernández et al., 2001).

Several nuclear genes coding for proteins active in the photosynthetic process (photosynthesis-related genes, PRGs) were found to be induced by the viral infection, namely chloroplast ferredoxin, photosystem II (PS II) subunit P2 and PS II reaction center W protein. Ferredoxin attends in the electron transport from photosystem I and in partitioning electrons to various enzymes (Fukuyama, 2004). Both PS II factors are required for assembly/stabilisation of the PS II complex. The concentration and/or activity of PRG-coded proteins use to be rather decreased in plant tissues during pathogen attacks (Bolton, 2009). In symptomatic chlorotic tissues of virus-infected plants the PRGs are down-regulated. As reported before, when light-dark mosaic symptoms occurred, photosynthetic apparatus was damaged only in chlorotic areas, the dark islands retained intact chloroplast structure and function (Chen et al., 2015). PPV-Rec isolate BOR-3 used in our experiments induced only dark green areas around the main veins on $N$. benthamiana leaves and slight downrolling of the leaf blades. Such symptom expression is not in contradiction with estimated transcriptional induction of several PRGs. The P2 subunit may also play a role in ROS-dependent signaling as sensor for singlet oxygen generated in chloroplasts (Brzezowski et al., 2012). 
Table 1. Up- and down-regulated genes of $N$. benthamiana by PPV infection as determined by subtractive cloning

\begin{tabular}{|c|c|c|c|}
\hline $\mathbf{I} / \mathbf{R}^{*}$ & Protein & BLAST hit details & \\
\hline I & metallothionein & Nicotiana tomentosiformis MT-like protein type 2 & XM_009608450.1 \\
\hline I & photosystem II subunit P2 & Nicotiana benthamiana chloroplast PsbP2 precursor & JF897608.1 \\
\hline I & ascorbate peroxidase & Nicotiana tomentosiformis APX & XM_009608760.1 \\
\hline I & ferredoxin & Nicotiana sylvestris chloroplast ferredoxin & XP_009796636.1 \\
\hline I & photosystem II reaction center W protein & Nicotiana sylvestris PSII RCW & XM_009799309.1 \\
\hline I & major latex protein & Nicotiana tomentosiformis kirola-like & XM_009613937.1 \\
\hline I & transcription factor HY5 & Nicotiana sylvestris transcription factor HY5 & XM_009770015.1 \\
\hline I & mitochondrial ribosomal protein & Nicotiana sylvestris $54 \mathrm{~S}$ ribosomal protein L19, mitochondrial-like & XM_009781628.1 \\
\hline I & ubiquitin-conjugating enzyme E2 & Nicotiana sylvestris UCE E2 2 & XM_009791022.1 \\
\hline I & phosphoinositide phospholipase C & Nicotiana sylvestris PI-PLC 6-like & XM_009785457.1 \\
\hline I & FRIGIDA-like protein & Nicotiana sylvestris FRL 4a & XM_009767899.1 \\
\hline I & dentin sialophosphoprotein-like & Nicotiana sylvestris DSPP & XM_009785372.1 \\
\hline $\mathrm{R}$ & defensine & Nicotiana excelsior $\gamma$-thionin & $\mathrm{AB} 005266.1$ \\
\hline $\mathrm{R}$ & protease inhibitor & Nicotiana tomentosiformis proteinase inhibitor I-B-like & XM_009607371.1 \\
\hline $\mathrm{R}$ & S-norcoclaurine synthase & Nicotiana sylvestris SNS-like & XM_009768642.1 \\
\hline $\mathrm{R}$ & chlorophyll a/b-binding protein & Nicotiana sylvestris $\mathrm{CAB}$ & AB012637.1 \\
\hline $\mathrm{R}$ & deSUMOylating isopeptidase & Nicotiana tomentosiformis deSUMO IP2-like & XM_009630754.1 \\
\hline $\mathrm{R}$ & glycine cleavage system $\mathrm{H}$ protein & Nicotiana tomentosiformis GCSH, mitochondrial-like & XM_009625854.1 \\
\hline $\mathrm{R}$ & $\beta$-galactosidase & Nicotiana tomentosiformis $\beta$-galactosidase & XM_009629241.1 \\
\hline $\mathrm{R}$ & high mobility protein $\mathrm{B} 2$ & Nicotiana tabacum HMGB2-like & EF051129.1 \\
\hline $\mathrm{R}$ & tetraspanin-like protein & Nicotiana sylvestris TLP & XM_009798164.1 \\
\hline $\mathrm{R}$ & chloroplast protein CP12 & Nicotiana tabacum CP12 & AF359459.2 \\
\hline $\mathrm{R}$ & unknown & Nicotiana tomentosiformis uncharacterized LOC104084708 & XM_009588631.1 \\
\hline $\mathrm{R}$ & unknown & Nicotiana sylvestris uncharacterized LOC104214887 & XM_009764610.1 \\
\hline
\end{tabular}

${ }^{\star} \mathrm{I}=$ induction, $\mathrm{R}=$ repression.

Kirola, the kiwifruit allergen belongs to the family of major latex proteins (MLPs) according to the sequence similarity, as do other kirola-like proteins from other species. X-ray diffraction and immunological studies showed their close structural relationship to pathogenesis-related proteins of the class PR-10 with a small but highly hydrophobic ligandbinding cavity (Chruszcz et al., 2013). Evidence for the MLP involvement in defensive responses to biotic and abiotic stresses has been demonstrated. MLP was abundant in both cotton root and hypocotyl tissues infected with Fusarium oxysporum (Dowd et al., 2004). Although its real function is unknown, MLP overexpression during fungal and viral infection, salt and drought stress, or toxin exposure has been confirmed (Chen and Dai, 2010; Malter and Wolf, 2011).

LONG HYPOCOTYL5 (HY5), a basic domain/leucine zipper protein, is the pivotal transcription factor for photomorphogenesis that is regulated by multiple photoreceptors. HY 5 binds to the promoters of a large number of genes that have diverse functions in plant growth and development including photosynthetic machinery assembly, photopigment production, chloroplast development, and seedling cotyledon expansion. Many of the regulated genes code also for transcription factors, often regulating expression of PRGs or circadian oscillators, so HY5 is probably a higher hierarchical regulator of the transcriptional cascade for photomorphogenesis (Lee et al., 2007). Induction of HY5 during PPV infection thus correlated with enhanced transcription levels of PRGs mentioned above.

A rise in respiration rate has been often observed in plant viral infections. The energy is needed both for virus replication and plant defense reactions, thus the infection is a highly energy-demanding process (Bolton, 2009). Key enzymes for oxidative phosphorylation are coded by mitochondrial DNA and expressed by mitochondrial proteosynthetic apparatus. Therefore, an enhanced production of mitochondrial ribosome compounds during viral infection is not surprising.

The ubiquitin (Ub)/26S proteasome system is the main proteolytic pathway in eukaryotes, which helps to remove abnormal proteins and regulates many cellular processes by targeted proteolysis of functional polypeptides. As such a general mechanism, ubiquitination is directly or indirectly involved in each biological process in plants and also plays a role in disease resistance signaling. It has also been shown usurped by several viruses to regulate their own replication in the host cell (Alcaide-Loridan and Jupin, 2012; Choi et al., 2013). The Ub-conjugating enzymes E2 are mediators of final Ub binding to proteins by E3 (Ub-ligating enzymes). E2 induction by heat or cadmium chloride treatment in tomato 
has been demonstrated (Feussner et al., 1997). Overexpression of E2 in transgenic $A$. thaliana enhanced the tolerance of drought stress (Wan et al., 2011). On the other hand, cotton leaf curl Multan geminivirus infection interferred with E2 and inhibited ubiquitination in planta (Eini et al., 2009).

Phosphoinositide-specific phospholipase C (PI-PLC) is an enzyme catalysing hydrolysis of phosphatidylinositol 4,5-bisphosphate into the second messengers inositol 1,4,5trisphosphate and diacylglycerol. It has been shown to be associated with signal transduction during various types of stress conditions including salt, drought and osmotic stress, as well as pathogen response (Rupwate and Rajasekharan, 2012). Although the mechanism is unclear, it may be indirectly connected with known PI-PLC influence on guard cell action related to stomatal regulation of gas flow (Mills et al., 2004). Dardick (2007) found PI-PLC rather repressed by PPV infection of $N$. benthamiana. This discrepancy may reflect different experimental conditions of these experiments (infection stage, virus isolate) and indicates various functions of PI-PLC in complex virus-host interactions.

Frigida of $A$. thaliana is known as an essential factor for regulation of flowering time. It prevents too early flowering by induction of the floral repressor through a cotranscriptional mechanism involving interaction with the nuclear cap-binding complex. However, several FRI families have been identified, which probably have separate biological roles (Risk et al., 2010). Nonfunctional FRI alleles had negative pleiotropic effect on plant fitness by reducing the numbers of nodes and branches on the inflorescence (Scarcelli et al., 2007). The role of several detected Frigida-like proteins (FRLs) in this process is unknown, although they are believed to be required, together with FRI, for the winter-annual habit. There is no evidence for their involvement in any pathogenor stress-related process and no significant delay in flowering of virus-infected plants was observed.

Dentin sialophosphoprotein (DSPP) is the precursor of two non-collagenous compounds of dentin (and to some extent of bone) tissues: dentin sialoprotein and dentin phosphoprotein, involved in dentinogenesis (Qin et al., 2002). Plant analogues of DSPP may take part e.g. in biomineralisation process at phytolith production. They have been transcriptionally induced in wheat infected by Fusarium graminearum, and involved in arsenic-tolerance of $A$. thaliana, so its function in plant metabolism under stress conditions cannot be excluded (Hill-Ambroz et al., 2006; Fu et al., 2014b).

Some genes influencing growth and cell division were repressed by PPV infection. Interestingly, several downregulated genes also coded for proteins participating in interactions with plant (mostly cellular) pathogens. It may reflect the dominance of the virus in some but not all „battles" of the molecular „war".

Plant defensins are small, cysteine-rich peptides that constitute a part of the innate immune system primarily directed against fungal pathogens. They are relatively abundant in seed coat, where during germination, they protect the seedlings from soil fungi. Defensins have been identified also in other tissues, mainly in peripheral cells and stomatal cells (Stotz et al., 2009). Pathogen- and other environmental stress-inducibility of defensins has been reported. Signaling pathways controlling these plant responses to microbial infection operate through the action of phytohormones like jasmonic acid (JA). During viral infection, however, JA-regulated gene expression is rather suppressed by RNA silencing (Hanks et al., 2005; Westwood et al., 2014). As a consequence, virus-infected plants may be more susceptible to secondary bacterial or fungal infections.

Plant protease inhibitors induced by wounding or microbial attacks are capable of suppressing enzymatic activity of phytopathogenic microorganisms or saliva of feeding insects (Ryan, 1990). Cystein proteases and their inhibitors are probably regulation elements of programmed cell death in plants (Solomon et al., 1999). Although some plant viruses (including potyviruses) use their own specific proteases in the genome expression strategy, there is no evidence of specific antiviral response by active protease inhibition. Down-regulated genes for protease inhibitors (similar to the defensin gene) in our experiment may reflect the complex situation, when some anti-fungal/anti-bacterial defense mechanisms are rather repressed, possibly to the detriment of anti-viral pathways.

S-norcoclaurine synthase (SNS) belongs to the group of pathogenesis-related proteins PR-10 participating in the defense of plants against microorganisms and fungi (Lee and Facchini, 2010). Its transcriptional repression fits the aforementioned picture. Transcription level of SNS declined also after opium poppy treatment by methyl jasmonate (Gurkok et al., 2014). It may indicate its negative regulation by JA-based defense reaction.

The nuclear gene for chlorophyll a/b-binding protein (CAB), a key photosynthesis factor, has been shown induced under drought stress conditions in faba bean (Abid et al., 2015). However, in most cases it was down-regulated in abiotic or biotic stress-suffered plants including transgenic tobacco plants expressing the full-length genome of tobacco mosaic virus (Jada et al., 2014). Experiments with retrograde signaling pathway mutant $A$. thaliana, where the $\mathrm{CAB}$ expression is uncoupled from the functional state of chloroplast, demonstrated that plastid signals controlling the expression of nuclear genes are necessary for defense responses to viral infection (Fu et al., 2014a).

DeSUMOylating isopeptidase IP2 is a C97 class cystein protease involved in Small ubiquitin-related modifier (SUMO)-mediated protein degradation. SUMOylation and deSUMOylation is a general post-translational regulatory mechanism of biological processes in plants including hormonal responses, flowering or defense against various 
types of stress. Disturbance of SUMO homeostasis causes abnormal control of the plant defense response: SUMO proteases may promote pathogen multiplication and delay the host response (Miura and Hasegawa, 2010). For example, SUMOylation of potyviral replicase has been shown to play a crucial role in the establishment of the infection (Xiong and Wang, 2013). Therefore, inhibition or repression of SUMO proteases can be regarded as manifestation of active plant defense.

Glycine cleavage system (GCS) is an enzyme complex bound to the inner mitochondrial membrane, taking part in glycine decarboxylation during respiration. The $\mathrm{H}$ protein (GCSH) with bound lipoic acid functions as a shuttle for some intermediate reaction products and interacts with other enzymes of the system. Involvement of GCS in plant defense response has been presumed, as its inhibition induced the production of ROS (Palmieri et al., 2010). GCSH level decreased in A. thaliana infected by Botrytis cinerea (Mulema et al., 2013). In cold- and drought-stressed pea plants, the loss of mitochondrial glycine oxidation capacity was correlated with GCSH delipoisation (Taylor et al., 2002).

$\beta$-galactosidases are glycosyl hydrolases commonly associated with the hydrolysis of lactose by mammals and E. coli. They also belong to the set of cell wall-degrading enzymes expressed by plant pathogenic fungi. $\beta$-galactosidase can release stored energy for rapid growth (xyloglucan mobilization in cotyledons), act at metabolic recycling of galactolipids and glycoproteins, or degrade cell wall components during senescence. It has been shown important for fruit ripening (Smith and Gross, 2000). However, scarce data are available about possible role of $\beta$-galactosidase in plant-pathogen interactions. Involvement of interactions between primary and secondary metabolism pathways cannot be excluded. Flavonoids are secondary metabolites involved in general stress tolerance of plants. They accumulate in vivo in form of glycosides, and a direct link between the production of flavonoids and sugars has been suggested (Pourcel et al., 2007). Significant negative correlation of $\beta$-galactosidase and flavonoid levels has been estimated by a study of cold stressed white clover (Rasmussen et al., 2006). Downregulation of $\beta$-galactosidase in pathogen-infected plants may increase the concentration of flavonoids, which act as scavengers of ROS.

Chromosomal high mobility group B proteins (HMGB) are characterized by a HMG-box DNA-binding domain flanked by a basic N-terminal and an acidic C-terminal domain. These non-histone chromatin-binding proteins act as versatile modulators of DNA function including influence on transcription and recombination (Pedersen and Grasser, 2010). The expression of HMGB genes was shown differentially regulated by stress and vice versa, plants overexpressing or lacking certain HMGB proteins displayed altered responses to stress treatment. Overexpression of
HMGB2 reduced Arabidopsis seed germination under salt and drought stress (Kwak et al., 2007). Its role in adaptation of plants to changing environmental conditions has been confirmed also with cold-suffering seabuckthorn (Ghangal et al., 2012). While HMGB2 has been induced by poliovirus infection in an animal model (Grinde et al., 2007), this is the first demonstration of its relation to a plant virus infection.

Animal tetraspanins are proteins with four transmembrane domains involved in intercellular communication with diverse functions in cell motility, proliferation, differentiation, cell fusion and signaling. Their fungal homologs (tetraspanin-like proteins, TLPs) are essential for penetration of fungal pathogens into leaves of the host plants (Clergeot et al., 2001; Gourgues et al., 2004). Function of structurally similar plant TLPs is still unknown, their involvement in male gamete-related processes during pollination has been hypothesized. Plant TLPs are essential for normal plant development, mutations of TLP gene resulted in severe pleiotropic defects in morphology affecting the shoot apical meristem (Wang et al., 2012). Thus, inhibition of TLP expression by viral infection may cause e.g. deformations, especially in evolving apical leaves due to faulty regulation of cell-growth and cell-positioning. Primary function of such inhibition may be repression of TLP-related signal transduction.

Chloroplast protein CP12 is a small, intrinsically disordered redox-sensitive protein expressed in a range of tissues including roots, flowers, and seeds, which influences carbohydrate partitioning. It has been hypothesized that CP12 acts to regulate metabolic pathways in response to changes in redox status in the chloroplast network. In higher plants its deficiency has a dramatic impact on the growth and morphology (loss of apical dominance, fused cotyledons, altered leaf morphology). CP12 has been shown to protect two enzymes of the Calvine-Benson cycle against oxidative stress (López-Calcagno et al., 2014). Moreover, transcriptome analysis of CP12-suppressed tobacco plants inter alia revealed induction of photosystem II reaction center $\mathrm{W}$ protein and metallothionein-like protein (both detected in our study), which may indicate functional connectivity between them in the frame of stress-related network (Howard et al., 2011).

Two of the repressed transcripts were assigned as „uncharacterized", however, one of them has been annotated as potential nucleoside-diphosphate kinase with a Pleckstrin homology domain. This domain binds phosphatidic acid, an early signal in the defense response.

We showed that despite some limits in effectivity, the simple subtraction cloning protocol leads to relevant results for comparison of differentially expressed genes on the transcriptional level. Low-range experiments of this type may validate and supplement the data obtained from extensive transcriptomic studies (Whitham et al., 2003). 
All our BLAST results referred to Nicotiana spp. and most of detected genes (with exception of FRL) have been connected with stress-related metabolism before. Induction of genes related to ROS production and signal transduction, and up-regulated JA-dependent pathways correlated well with known antiviral defense processes. Other pathways directed mainly against fungal or bacterial pathogens were rather down-regulated, and some repressed genes could be connected with manifestation of macroscopic symptoms of viral infection.

Comparative transcriptomics shows only the differences in gene expression but it cannot elucidate the causal connections and mechanisms of interactions leading to the status quo. Complex picture involves direct viral usurpation of cellular machinery, host defense reactions, as well as virusinduced repression of these reactions. In natural compatible virus-host systems the interactions reflect long-term coevolution of both entities.

The stone fruit trees (Prunus spp.) are natural hosts of PPV. Although systemically infected, the trees show notable variation of virus and symptom distribution, in particular in sprouts and leaves (Šubr and Glasa, 2008). Analysis of peach (P. persica) gene expression in response to PPV infection using massive cDNA sequencing showed different changes of expression profiles in symptomatic and non-symptomatic leaves compared to healthy control. In non-symptomatic leaves, three-times more genes have been found affected by PPV infection (huge majority of them up-regulated) then in leaves showing symptoms (with similar number of up- and down-regulated genes) (Rubio et al., 2015). Only few hits corresponding to our results have been recorded, mainly in leaves without symptoms (ferredoxin and MLP; some genes were found regulated in opposite way - MT, CAB and $\beta$-galactosidase).

Arabidopsis thaliana, a widely used model species in plant genomics, has also been studied for transcriptome alteration by PPV infection (Babu et al., 2008). PI-PLC and DSPP-like protein were the only hits of that work corresponding to our results. MT, ferredoxin and MLP were down-regulated, $\beta$-galactosidase and HMG proteins up-regulated (opposite to our finding) (Babu et al., 2008).

Changes of $N$. benthamiana transcriptome caused by three different viruses including PPV have been analysed by microarray technology (Dardick, 2007). Significant overlap of influenced genes has been recorded, although their number correlated with severity of symptoms induced by respective viruses. Extensive supplementary data of that work involve seven genes corresponding to our results (induction of MT, APX, Ub-conjugating enzyme, DSPP-like protein, repression of proteinase inhibitors, $\mathrm{CAB}$ and $\beta$-galactosidase). Several SUMO proteins have been induced by PPV infection (Dardick, 2007), while deSUMOylating enzyme was shown to be down-regulated in our results, both indicating involvement of SUMOylation in the PPV infection cycle. Three up-regulated genes from our work (ferredoxin, PS II reaction center $\mathrm{W}$ protein and $54 \mathrm{~S}$ ribosomal protein L19) were shown influenced by Tomato ringspot virus but not by PPV (Dardick, 2007).

PPV-induced regulation of particular plant genes obviously depends on the host species. Best match of the transcriptome modifications we described was obtained with data from N. benthamiana. It is a non-natural host, not evolutionary adapted to PPV infection. However, there are several benefits of this artificial virus-host system (Goodin et al., 2008). The infection is systemic and PPV is relatively uniformly spread in all host tissues few days after infection (contrary to Prunus spp. hosts). Thus the experiments are more reproducible and require much less time, the plant maintenance and sample preparation are simple and fast. Of course, obtained results do not necessarily reflect interactions of the virus with its natural host, however, they contribute to the general knowledge about infection-induced changes of gene expression in plants.

Acknowledgements. The research was supported by the grant 2/0001/15 from the Scientific Grant Agency of Ministry of Education and Slovak Academy of Sciences (VEGA).

\section{References}

Abid G, Muhovski Y, Mingeot D, Watillon B, Toussaint A, Mergeai G, M'hamdi M, Sassi K, Jebara M (2015): Identification and characterization of drought stress responsive genes in faba bean (Vicia faba L.) by suppression subtractive hybridization. Plant Cell Tiss. Org. 121, 367-379.

Alcaide-Loridan C, Jupin I (2012): Ubiquitin and plant viruses, let's play together! Plant Physiol. 160, 72-82. http://dx.doi. org/10.1104/pp.112.201905

Agrawal GK, Jwa NS, Iwahashi H, Rakwal R (2003): Importance of ascorbate peroxidases OsAPX1 and OsAPX2 in the rice pathogen response pathways and growth and reproduction revealed by their transcriptional profiling. Gene 322, 93-103. http://dx.doi.org/10.1016/j.gene.2003.08.017

Babu M, Griffiths JS, Huang TS, Wang A (2008): Altered gene expression changes in Arabidopsis leaf tissues and protoplasts in response to Plum pox virus infection. BMC Genomics 9, 325. http://dx.doi.org/10.1186/1471-2164 $-9-325$

Brzezowski P, Wilson KE, Gray GR (2012): The PSBP2 protein of Chlamydomonas reinhardtii is required for singlet oxygen-dependent signaling. Planta 236, 1289-1303. http://dx.doi.org/10.1007/s00425-012-1683-1

Bolton MD (2009): Primary metabolism and plant defense-fuel for the fire. Mol. Plant Microbe In. 22, 487-497. http:// dx.doi.org/10.1094/MPMI-22-5-0487

Carginale V, Maria G, Capasso C, Ionata E, La Cara F, Pastore M, Bertaccini A, Capasso A (2004): Identification of genes expressed in response to phytoplasma infection in leaves 
of Prunus armeniaca by messenger RNA differential display. Gene 332, 29-34. http://dx.doi.org/10.1016/j. gene.2004.02.030

Caverzan A, Passaia G, Rosa SB, Ribeiro CW, Lazzarotto F, MargisPinheiro M (2012): Plant responses to stresses: role of ascorbate peroxidase in the antioxidant protection. Genet. Mol. Biol. 35, 1011-1019. http://dx.doi.org/10.1590/ $\underline{\text { S1415-47572012000600016 }}$

Chen JY, Dai XF (2010): Cloning and characterization of the Gossypium hirsutum major latex protein gene and functional analysis in Arabidopsis thaliana. Planta 231, 861-873. http://dx.doi.org/10.1007/s00425-009-1092-2

Chen LJ, Liu J, Zhao FF, Li JY, Wang SX, Lin HH, Xi DH (2015): Characterisation of the dark green islands of cucumber mosaic virus infected Nicotiana tabacum. Plant Cell Rep. 34, 1225-1238. http://dx.doi.org/10.1007/s00299015-1781-1

Choi D, Kim HM, Yun HK, Park JA, Kim WT, Bok SH (1996): Molecular cloning of a metallothionein-like gene from Nicotiana glutinosa L. and its induction by wounding and tobacco mosaic virus infection. Plant Physiol. 112, 353-359. http://dx.doi.org/10.1104/pp.112.1.353

Choi AG, Wong J, Marchant D, Luo H (2013): The ubiquitin-proteasome system in positive-strand RNA virus infection. Rev. Med. Virol. 23, 85-96. http://dx.doi.org/10.1002/ $\underline{\text { rmv. } 1725}$

Chruszcz M, Ciardiello MA, Osinski T, Majorek KA, Giangrieco I, Font J, Breitenederd H, Thalassinos K, Minor W (2013): Structural and bioinformatic analysis of the kiwifruit allergen Act d 11, a member of the family of ripeningrelated proteins. Mol. Immunol. 56, 794-803. http:// dx.doi.org/10.1016/j.molimm.2013.07.004

Clergeot PH, Gourgues M, Cots J, Laurans F, Latorse MP, Pépin R, Tharreau D, Notteghem JL, Lebrun MH (2001): PLS1, a gene encoding a tetraspanin-like protein, is required for penetration of rice leaf by the fungal pathogen Magnaporthe grisea. Proc. Natl. Acad. Sci. USA 98, 6963-6968. http://dx.doi.org/10.1073/ pnas. 111132998

Dardick C (2007): Comparative expression profiling of Nicotiana benthamiana leaves systemically infected with three fruit tree viruses. Mol. Plant Microbe In. 20, 1004-1017. http:// dx.doi.org/10.1094/MPMI-20-8-1004

Gourgues M, Brunet-Simon A, Lebrun MH, Levis C (2004): The tetraspanin $\mathrm{BcPls} 1$ is required for appressorium-mediated penetration of Botrytis cinerea into host plant leaves. Mol. Microbiol. 51, 619-629. http://dx.doi.org/10.1046/j.13652958.2003.03866.x

Dadakova K, Havelkova M, Kurkova B, Tlolkova I, Kasparovsky T, Zdrahal Z, Lochman J (2015): Proteome and transcript analysis of Vitis vinifera cell cultures subjected to Botrytis cinerea infection. J. Proteomics 119, 143-153. http:// dx.doi.org/10.1016/j.jprot.2015.02.001

Dowd C, Wilson IW, McFadden H (2004): Gene expression profile changes in cotton root and hypocotyl tissues in response to infection with Fusarium oxysporum $\mathrm{f}$. sp. vasinfectum. Mol. Plant Microbe In.17, 654-667. http://dx.doi. org/10.1094/MPMI.2004.17.6.654
Eini O, Dogra S, Selth LA, Dry IB, Randles JW, Rezaian MA (2009): Interaction with a host ubiquitin-conjugating enzyme is required for the pathogenicity of a geminiviral DNA $\beta$ satellite. Mol. Plant Microbe In. 22, 737-746. http:// dx.doi.org/10.1094/MPMI-22-6-0737

Feussner K, Feussner I, Leopold I, Wasternack C (1997): Isolation of a cDNA coding for an ubiquitin-conjugating enzyme UBC1 of tomato - the first stress-induced UBC of higher plants. FEBS Lett. 409, 211-215. http://dx.doi. org/10.1016/S0014-5793(97)00509-7

Fu FQ, Zhang DW, Deng XG, Li JY, Peng XJ, Tang H, Lin HH (2014a): Role of plastid signals in modulating Arabidopsis responses to Cucumber mosaic virus. Plant Growth Regul. 75, 761-769. http://dx.doi.org/10.1007/s10725014-9979-8

Fu SF, Chen PY, Nguyen QTT, Huang LY, Zeng GR, Huang TL, Lin CY, Huang HJ (2014b): Transcriptome profiling of genes and pathways associated with arsenic toxicity and tolerance in Arabidopsis. BMC Plant Biol. 14, 94. http:// dx.doi.org/10.1186/1471-2229-14-94

Fukuyama K (2004): Structure and function of plant-type ferredoxins. Photosynth. Res. 81, 289-301. http://dx.doi. org/10.1023/B:PRES.0000036882.19322.0a

Ghangal R, Raghuvanshi S, Sharma PC (2012): Expressed sequence tag based identification and expression analysis of some cold inducible elements in seabuckthorn (Hippophae rhamnoides L.). Plant Physiol. Bioch. 51, 123-128. http:// dx.doi.org/10.1016/j.plaphy.2011.10.005

Glasa M, Palkovics L, Kominek P, Labonne G, Pittnerova S, Kudela O, Candresse T, Subr Z (2004): Geographically and temporally distant natural recombinant isolates of Plum pox virus (PPV) are genetically very similar and form a unique PPV subgroup. J. Gen. Virol. 85, 2671-2681. http://dx.doi. org/10.1099/vir.0.80206-0

Glasa M, Predajňa L, Šubr Z (2010): Competitiveness of different Plum pox virus isolates in experimental mixed infection reveals rather isolate- than strain-specific behaviour. J. Plant Pathol. 92, 267-271.

Goodin MM, Zaitlin D, Naidu RA, Lommel SA (2008): Nicotiana benthamiana: Its history and future as a model for plantpathogen interactions. Mol. Plant Microbe In. 21, 10151026. http://dx.doi.org/10.1094/MPMI-21-8-1015

Grinde B, Gayorfar M, Hoddevik G (2007): Modulation of gene expression in a human cell line caused by poliovirus, vaccinia virus and interferon. Virol. J. 4, 24. http://dx.doi. org/10.1186/1743-422X-4-24

Gurkok T, Turktas M, Parmaksiz I, Unver T (2014): Transcriptome profiling of alkaloid biosynthesis in elicitor induced opium poppy. Plant Mol. Biol. Rep. 33, 673-688. http:// dx.doi.org/10.1007/s11105-014-0772-7

Haft DH (2015): Using comparative genomics to drive new discoveries in microbiology. Curr. Opin. Microbiol. 23, 189-196. http://dx.doi.org/10.1016/j.mib.2014.11.017

Hanks JN, Snyder AK, Graham MA, Shah RK, Blaylock LA, Harrison MJ, Shah DM (2005): Defensin gene family in Medicago truncatula: structure, expression and induction by signal molecules. Plant Mol. Biol. 58, 385-399. http:// dx.doi.org/10.1007/s11103-005-5567-7 
Hernández JA, Talavera JM, Martínez-Gómez P, Dicenta F, Sevilla F (2001): Response of antioxidative enzymes to plum pox virus in two apricot cultivars. Physiol. Plantarum 111, 313-321. http://dx.doi.org/10.1034/j.1399-3054 $.2001 .1110308 . \mathrm{x}$

Hill-Ambroz K, Webb CA, Matthews AR, Li W, Gill BS, Fellers JP (2006): Expression analysis and physical mapping of a cDNA library of Fusarium head blight infected wheat spikes. Crop Sci. 46, S-15. http://dx.doi.org/10.2135/ cropsci2005.07.0206tpg

Howard TP, Upton GJ, Lloyd JC, Raines CA (2011): Antisense suppression of the small chloroplast protein $\mathrm{CP} 12$ in tobacco: a transcriptional viewpoint. Plant Signal. Behav. 6, 2026-2030. http://dx.doi.org/10.4161/psb.6.12.18055

Jada B, Soitamo AJ, Siddiqui SA, Murukesan G, Aro EM, Salakoski T, Lehto K (2014): Multiple Different Defense Mechanisms Are Activated in the Young Transgenic Tobacco Plants Which Express the Full Length Genome of the Tobacco Mosaic Virus, and Are Resistant against this Virus. PLOS One 9, e107778. http://dx.doi.org/10.1371/ journal.pone. 0107778

Kamencayová M, Košík I, Hunková J, Šubr ZW (2014): Transient expression of the influenza A virus PB1-F2 protein using a plum pox virus-based vector in Nicotiana benthamiana. Acta Virol. 58, 274-277. http://dx.doi.org/10.4149/ av $2014 \quad 03 \quad 274$

Kim S, Ahn IP, Lee YH (2001): Analysis of genes expressed during rice-Magnaporthe grisea interactions. Mol. Plant Microbe In. 14, 1340-1346. http://dx.doi.org/10.1094/ MPMI.2001.14.11.1340

Kwak KJ, Kim JY, Kim YO, Kang H (2007): Characterization of transgenic Arabidopsis plants overexpressing high mobility group B proteins under high salinity, drought or cold stress. Plant Cell Physiol. 48, 221-231. http://dx.doi. org $/ 10.1093 / \mathrm{pcp} / \mathrm{pcl} 057$

Lee EJ, Facchini P (2010): Norcoclaurine synthase is a member of the pathogenesis-related 10/Bet v1 protein family. Plant Cell 22, 3489-3503. http://dx.doi.org/10.1105/ tpc. 110.077958

Lee J, He K, Stolc V, Lee H, Figueroa P, Gao Y, Tongprasit W, Zhao H, Lee I, Deng XW (2007): Analysis of transcription factor HY5 genomic binding sites revealed its hierarchical role in light regulation of development. Plant Cell 19, 731-749. http://dx.doi.org/10.1105/tpc.106.047688

Leszczyszyn OI, Imam HT, Blindauer CA (2013): Diversity and distribution of plant metallothioneins: a review of structure, properties and functions. Metallomics, 5, 1146-1169. http://dx.doi.org/10.1039/c3mt00072a

López-Calcagno PE, Howard TP, Raines CA (2014): The CP12 protein family: a thioredoxin-mediated metabolic switch? Front. Plant Sci. 5, 9. http://dx.doi.org/10.3389/ fpls.2014.00009

Malter D, Wolf S (2011): Melon phloem-sap proteome: developmental control and response to viral infection. Protoplasma 248, 217-224. http://dx.doi.org/10.1007/ $\underline{\text { s00709-010-0215-8 }}$

Mills LN, Hunt L, Leckie CP, Aitken FL, Wentworth M, McAinsh MR, Gray JE, Hetherington AM (2004): The effects of ma- nipulating phospholipase C on guard cell ABA囚signalling. J. Exp. Bot. 55, 199-204. http://dx.doi.org/10.1093/jxb/ $\underline{\text { erh027 }}$

Miura K, Hasegawa PM (2010): Sumoylation and other ubiquitinlike post-translational modifications in plants. Trends Cell Biol. 20, 223-232. http://dx.doi.org/10.1016/j. tcb.2010.01.007

Mulema JM, Okori P, Denby KJ (2013): Proteomic analysis of the Arabidopsis thaliana-Botrytis cinerea interaction using two-dimensional liquid chromatography. Afr. J. Biotechnol. 10, 17551-17563.

Palmieri MC, Lindermayr C, Bauwe H, Steinhauser C, Durner J (2010): Regulation of plant glycine decarboxylase by Snitrosylation and glutathionylation. Plant Physiol. 152, 1514-1528. http://dx.doi.org/10.1104/pp.109.152579

Pedersen DS, Grasser KD (2010): The role of chromosomal HMGB proteins in plants. BBA Gene Regulatory Mechanisms 1799, 171-174. http://dx.doi.org/10.1016/j. bbagrm.2009.11.004

Pérez-Clemente RM, Montoliu A, Vives V, López-Climent MF, Gómez-Cadenas A (2015): Photosynthetic and antioxidant responses of Mexican lime (Citrus aurantifolia) plants to Citrus tristeza virus infection. Plant Pathol. 64, 16-24. http://dx.doi.org/10.1111/ppa.12241

Pourcel L, Routaboul JM, Cheynier V, Lepiniec L, Debeaujon I (2007): Flavonoid oxidation in plants: from biochemical properties to physiological functions. Trends Plant Sci. 12, 29-36. http://dx.doi.org/10.1016/j.tplants.2006.11.006

Predajňa L, Nagyová A, Šubr Z (2010): A simple and efficient biolistic procedure of plant transfection with cDNA clons of RNA viruses. Acta Virol. 54, 303-306. http://dx.doi. org/10.4149/av_2010_04_303

Qin C, Brunn JC, Cadena E, Ridall A, Tsujigiwa H, Nagatsuka H, Nagai N, Butler WT (2002): The expression of dentin sialophosphoprotein gene in bone. J. Dental Res. 81, 392394. http://dx.doi.org/10.1177/154405910208100607

Rasmussen S, Cao M, Fraser K, Koulman A, Park-Ng Z, Xue H, Lane $G$ (2006): Cold stress in white clover - an integrated view of metabolome and transcriptome responses. Proceedings of the 13th Australasian Plant Breeding Conference, Christchurch, New Zealand, 750-757.

Risk JM, Laurie RE, Macknight RC, Day CL (2010): FRIGIDA and related proteins have a conserved central domain and family specific $\mathrm{N}$-and $\mathrm{C}$-terminal regions that are functionally important. Plant Mol. Biol. 73, 493-505. http:// dx.doi.org/10.1007/s11103-010-9635-2

Rubio M, Rodríguez-Moreno L, Ballester AR, Moura MC, Bonghi C, Candresse T, Martínez-Gómez P (2015): Analysis of gene expression changes in peach leaves in response to Plum pox virus infection using RNA-Seq. Mol. Plant Pathol. 16, 164-176. http://dx.doi.org/10.1111/mpp.12169

Rupwate SD, Rajasekharan R (2012): Plant phosphoinositidespecific phospholipase C: an insight. Plant Signal. Behav. 7, 1281-1283. http://dx.doi.org/10.4161/psb.21436

Ryan CA (1990): Protease inhibitors in plants: genes for improving defenses against insects and pathogens. Ann. Rev. Phytopathol. 28, 425-449. http://dx.doi.org/10.1146/annurev. py.28.090190.002233 
Scarcelli N, Cheverud JM, Schaal BA, Kover PX (2007): Antagonistic pleiotropic effects reduce the potential adaptive value of the FRIGIDA locus. Proc. Natl. Acad. Sci. USA 104, 16986-16991. http://dx.doi.org/10.1073/ pnas.0708209104

Solomon M, Belenghi B, Delledonne M, Menachem E, Levine A (1999): The involvement of cysteine proteases and protease inhibitor genes in the regulation of programmed cell death in plants. Plant Cell 11, 431-443. http://dx.doi. org/10.1105/tpc.11.3.431

Smith DL, Gross KC (2000): A family of at least seven $\beta$-galactosidase genes is expressed during tomato fruit development. Plant Physiol. 123, 1173-1184. http://dx.doi.org/10.1104/ pp.123.3.1173

Stotz HU, Thomson J, Wang Y (2009): Plant defensins: defense, development and application. Plant Signal. Behav. 4, 1010-1012. http://dx.doi.org/10.4161/psb.4.11.9755

Šubr Z, Glasa M (2008): Plum pox virus variability detected by the advanced analytical methods. Acta Virol. 52, 75-90.

Šubr ZW, Kastirr U, Kühne T (2002): Subtractive cloning of DNA from Polymyxa graminis - an obligate parasitic plasmodiophorid. J. Phytopathol. 150, 564-568. http://dx.doi. org/10.1046/j.1439-0434.2002.00795.x

Šubr ZW, Predajňa L, Glasa M (2012): Genome sequence variability of a Plum pox virus isolate related to its long-time multiplication in different host species. Petria 22, 304.

Taylor NL, Day DA, Millar AH (2002): Environmental stress causes oxidative damage to plant mitochondria leading to inhibi- tion of glycine decarboxylase. J. Biol. Chem. 277, 4266342668. http://dx.doi.org/10.1074/jbc.M204761200

Wan X, Mo A, Liu S, Yang L, Li L (2011): Constitutive expression of a peanut ubiquitin-conjugating enzyme gene in Arabidopsis confers improved water-stress tolerance through regulation of stress-responsive gene expression. J. Biosci. Bioengin. 111, 478-484. http://dx.doi.org/10.1016/j. jbiosc.2010.11.021

Wang F, Vandepoele K, Van Lijsebettens M (2012): Tetraspanin genes in plants. Plant Sci. 190, 9-15. http://dx.doi. org/10.1016/i.plantsci.2012.03.005

Westwood JH, Lewsey MG, Murphy AM, Tungadi T, Bates A, Gilligan CA, Carr JP (2014): Interference with jasmonic acid-regulated gene expression is a general property of viral suppressors of RNA silencing but only partly explains virus-induced changes in plant-aphid interactions. J. Gen. Virol. 95, 733-739. http://dx.doi.org/10.1099/ vir.0.060624-0

Whitham SA, Quan S, Chang HS, Cooper B, Estes B, Zhu T, Wang X, Hou YM (2003): Diverse RNA viruses elicit the expression of common sets of genes in susceptible Arabidopsis thaliana plants. Plant J. 33, 271-283. http:// dx.doi.org/10.1046/j.1365-313X.2003.01625.x

Xiong R, Wang A (2013): SCE1, the SUMO-conjugating enzyme in plants that interacts with NIb, the RNA-dependent RNA polymerase of Turnip mosaic virus, is required for viral infection. J. Virol. 87, 4704-4715. http://dx.doi. org/10.1128/JVI.02828-12 